\title{
Should There Be Sex-Specific Criteria for the Diagnosis and Treatment of Heart Failure?
}

\author{
Lawrence E. Greiten • Sara J. Holditch • Shivaram Poigai Arunachalam • \\ Virginia M. Miller
}

Received: 6 August 2013 / Accepted: 7 October 2013 / Published online: 9 November 2013

(C) The Author(s) 2013. This article is published with open access at Springerlink.com

\begin{abstract}
All-cause mortality from cardiovascular disease is declining in the USA. However, there remains a significant difference in risk factors for disease and in mortality between men and women. For example, prevalence and outcomes for heart failure with preserved ejection fraction differ between men and women. The reasons for these differences are multifactorial, but reflect, in part, an incomplete understanding of sex differences in the etiology of cardiovascular diseases and a failure to account for sex differences in pre-clinical studies including those designed to develop new diagnostic and treatment modalities. This review focuses on the underlying physiology of these sex differences and provides evidence that inclusion of female animals in pre-clinical studies of heart failure and in development of imaging modalities to assess cardiac function might provide new information from which one could develop sex-specific diagnostic criteria and approaches to treatment.
\end{abstract}

Keywords Diastolic dysfunction · Heart failure with preserved ejection fraction - Magnetic resonance imaging · MRI

Associate Editor Jennifer L. Hall oversaw the review of this article

L. E. Greiten • V. M. Miller $(\bowtie)$

Department of Surgery, Mayo Clinic, Med Sci 4-62, 200 First St SW,

Rochester, MN 55905, USA

e-mail: miller.virginia@mayo.edu

S. J. Holditch

Department of Virology and Gene Therapy, Mayo Clinic,

Rochester, MN, USA

S. P. Arunachalam

Department of Radiology, Mayo Clinic, Rochester, MN, USA

V. M. Miller

Department of Physiology and Biomedical Engineering,

Mayo Clinic, Rochester, MN, USA

\section{Introduction}

Sex and gender differences are recognized in the incidence, clinical presentation, and mortality associated with cardiovascular disease $[1,2]$. Unfortunately, sex-specific diagnostic and treatment modalities have yet to gain similar attention which, in part, reflect incomplete understanding of physiological and cellular mechanisms contributing to sex differences in etiology of some cardiovascular diseases and failure to consider sex differences in pharmacokinetics and pharmacodynamics of drugs used to treat most cardiovascular diseases $[3,4]$. Progress in understanding these mechanisms is slow due to the continued use of male animals in many types of experiments, lack of reporting of the sex and hormonal status of animals and cells used in mechanistic studies, and the absence of reporting of clinical trial results by sex or gender [5-7].

The incidence of heart failure for persons after the age of 65 years approaches 10 per 1,000 population. Although the prevalence of heart failure for persons $>20$ years of age is greater for males $(2.5 \%)$ than females $(1.8 \%)$, all age mortality for women $(58.2 \%)$ exceeds that of men (41.8\%) [2]. Heart failure can be classified as that with reduced ventricular ejection fraction or with preserved ejection fraction (HFpEF). The proportion of people with HFpEF has increased over time and while survival has improved for persons with reduced ventricular ejection fraction, a similar trend is not seen with individuals diagnosed with HFpEF. Risk factors for development of $\mathrm{HFpEF}$ include hypertension, renal insufficiency, and obesity in women, whereas myocardial ischemia, atrial fibrillation, and chronic obstructive pulmonary disease are risk factors for development of $\mathrm{HFpEF}$ in men $[8,9]$. Adverse outcomes from HFpEF for men exceed that of women $[10,11]$. There are no specific evidence-based therapies to treat HFpEF [4, 12]. The absence of such therapies reflects research that has focused on the endstage condition and the absence of data linking sex differences 
in causal risk factors to end organ structure and performance. For example, there is a paucity of data linking underlying factors contributing to development of hypertension, a risk factor for HFpEF in women, with investigation of cardiac remodeling affecting ventricular function in female animals. Alternatively, studies of cardiac function have ignored the temporal changes in stimuli (i.e., hypertension) or signaling pathways leading to the end-stage condition and have not taken into account sex and hormonal status of the experimental material [13]. This review will focus on studies investigating the contribution of sex and sex steroid hormones to hypertension and cardiac remodeling along with modalities to assess left ventricular function. Limitations in current research and recommendations for future areas of study will be presented.

\section{Etiology of Sex Differences}

The fundamental genetic basis of sex differences is the complement of sex chromosomes: $\mathrm{XY}$ for males and $\mathrm{XX}$ for females. About $95 \%$ of the $\mathrm{Y}$ chromosome is considered the male-specific region that does not recombine with the $\mathrm{X}$ chromosome during meiosis. It is inherited directly from father to sons. Several genes on this chromosome are associated with several cardiovascular risk factors including blood pressure, and low-density lipoprotein cholesterol [14, 15]. In men of European lineages, increased risk of myocardial infarction is also associated with variants on the male-specific region $\mathrm{Y}$ chromosome related to adaptive immunity [16].

The Y chromosome is required for development of the testes, the main source of testosterone in men. However, responsiveness to testosterone requires the androgen receptor which is located on the $\mathrm{X}$ chromosome. Because of mosaic inactivation of one of the $\mathrm{X}$ chromosomes in females, polymorphisms in genes on portions of the $\mathrm{X}$ chromosome will not be expressed in all tissues as they would be in males. Thus, $X$ inactivation results in greater variability in phenotypes in females than males for X-linked traits [17]. The greater variability of physiological responses in females is used to justify exclusion of female animals from many basic science studies. However, expected variability can be accommodated with appropriate experimental design [18].

The primary source of sex steroid hormones is the testes for males and the ovaries for females. Sex steroid hormones affect gene transcription, termed genomic effects, and more rapid transient effects, termed non-genomic effects. Phenotypic expression of these effects can be classified as organizational, i.e., phenotypes which remain after removal of the gonads or deficiencies in sex hormones, or activational, i.e., phenotypes which are reversible with removal and replacement of the specific sex steroid hormone. Thus, sex differences in etiology of cardiovascular disease will reflect the combined contribution of the chromosomal complement, and organizational and activational effects of sex steroid hormones. In females, the cardiovascular system adapts to the circulatory demands of a developing fetus. Therefore, underlying mechanisms of autonomic control of vascular resistance and cardiac function, volume regulation, and vascular/cardiac remodeling will differ from males. Accounting for organization and activational effects of hormones in experimental design requires attention to hormonal status and pregnancy history.

Sex Differences in Cellular and Molecular Characterization Linking Hypertension to Cardiac Remodeling

In all ethnic groups, young males tend to have higher mean systolic and diastolic blood pressures than age-matched females, and through middle age, the prevalence of hypertension is higher among males than females. However, with advancing age, the prevalence of hypertension increases in females, ultimately surpassing that of age-matched males [1, 19-23]. Compared to normotensive controls, blood pressure is proportionally higher in stage 1 hypertensive premenopausal women than in age-matched men and could have a greater impact on target organ systems [24]. Nearly $75 \%$ of post-menopausal women in the USA are affected by some degree of essential hypertension [25, 26]. The relationship for development of hypertension in women associated with estrogen deficiency at menopause points to activational effects of the sex steroids in regulation of blood pressure.

Since blood pressure is lower in premenopausal compared to postmenopausal females, hypertension may proportionally impose a greater hemodynamic load on the heart in young-tomiddle-aged females when compared to age-matched males, and thus, contribute to greater ventricular remodeling with hypertension [27-33]. In women, cardiac remodeling in response to increased volume load associated with pregnancy is adaptive. However, with aging and development of hypertension, mechanisms required for cardiac remodeling in pregnancy could become maladaptive. For example, women who experience hypertensive disorders of pregnancy have higher risk for hypertension and other cardiovascular diseases as they age $[34,35]$.

Chronic hypertension leading to heart failure involves persistent activation of the neuron-hormonal axis, microvascular abnormalities affecting loss of functional myocytes via apoptosis and fibroblast proliferation, excessive volume and pressure imposed on remaining viable myocardium and alterations in the extracellular matrix of the myocardium, i.e., myocardial remodeling [36-39]. Heart failure in males also frequently follows myocardial ischemia or infarctions and mirrors early myocardial remodeling during the transition from hypertension to heart failure. Most mechanistic studies linking these processes have not focused 
on sex differences that might affect disease progression. If sex differences are addressed, the focus is on the contribution of sex steroid hormones and not on concomitant influence of sex chromosomal complement. With this in mind; the following sections will focus on sex differences in components of the cardiovascular system most likely involved in the progression of both hypertension and heart failure.

\section{Autonomic Nervous System}

Sex differences in autonomic function reflect genetic factors dictated in part by the $\mathrm{Y}$ chromosome. The locus for Sry genes on the $\mathrm{Y}$ chromosome affects development of the testes in males, but these genes also affect regulation of tyrosine hydroxylase, an enzyme necessary in the synthesis of norepinephrine [40, 41]. However, activity of tyrosine hydroxylase, transport and disposition of norepinephrine are also affected by the sex steroid hormone, estrogen, in the periphery and in the brain [42-46]. Consequently, both sex and hormonal status will affect responses to autonomic stimulation.

Total peripheral resistance is directly proportional to sympathetic nerve stimulation in young men [47]. However, a similar direct relationship is not apparent in young women, but becomes evident in post-menopausal women and in young women following blockade of $\beta$-adrenergic receptors. These observations suggest that female sex steroids modulate the response to sympathetic activation and may involve $\beta$ adrenergic receptors [48, 49].

Other studies also suggest that changes in adrenergic neurotransmission would provide insight into sex differences in autonomic regulation of the heart. For example, heart rate variability decreases in women at menopause $[50,51]$. In postmenopausal women with normal ventricular ejection fraction and those with systolic dysfunction (heart failure with reduced ejection fraction), cardiac-specific sympathetic activation and cardiac norepinephrine spillover was greater than in agematched men [52]. Similar comparisons have not been made between premenopausal women and age-matched men or between post-menopausal women with and without HFpEF and age-matched men but perhaps would provide information to better direct adrenergic related therapies.

Baroreflex sensitivity also is altered by estrogenic hormones, thus modulating peripheral resistance during the menstrual cycle, pregnancy, and menopause [53-57]. Although the hormonal shifts of pregnancy modulate neurotransmission and baroreflex control, hypertension may precede pregnancy or develop during the course of pregnancy in the form of pregnancy-induced hypertension, preeclampsia, or eclampsia [58]. It is unclear at this time whether hormonal shifts of pregnancy expose an underlying condition or if other factors associated with defects in the fetal-maternal circulation precipitate the condition. While one or the other or both may be causal, hypertensive disorders of pregnancy increase the life-long risk for development of hypertension and other cardiovascular pathologies including atrial fibrillation and heart failure later in life [34, 59]. Specific associations between hypertensive disorders of pregnancy and HFpEF remain to be established and the underlying mechanisms need to be explored in order to develop appropriate monitoring and risk management strategies to reduce overall cardiovascular risk for women as they age.

\section{Endothelium and Nitric Oxide}

Local control of vascular tone and microcirculatory function is modulated by factors released from the endothelium. Endothelium-derived nitric oxide is one major contributor to counteracting sympathetic-mediated vasoconstriction. In general, loss of nitric oxide is a hallmark of endothelial dysfunction. In addition to modulating vascular tone, nitric oxide inhibits cell proliferation and inhibits activation of platelets and adhesion of monocytes to the endothelium. The loss of these inhibitory functions contributes to a procoagulatory and pro-inflammatory condition leading to constriction of coronary arteries and the provocation of myocardial ischemia and micro-vascular disease (Fig. 1) [60].

Non-laminar shear stresses resulting from arterial occlusion further down regulates expression of endothelial nitric oxide (eNOS) while at the same time increasing release of inflammatory cytokines and oxidative stress. Together, these processes would function as a potential positive feedback loop exacerbating disease processes [61].

Within the myocardium, local synthesis of nitric oxide may prevent endomyocardial fibrosis by blocking the signaling cascade involving endothelin, angiotensin II, aldosterone, and transforming growth factor $\beta$ [62]. In addition, excitation-relaxation processes in the myocyte are affected through nitric oxide mediated increases in cGMP-induced phosphorylation of troponin. This phosphorylation facilitates calcium-independent diastolic cross-bridge cycling, posttranslational modifications of titan and, thus, concomitant myocardium diastolic stiffening [63].

Results of several studies indicate a contribution of cGMP in regulation of cardiac functioning. In men with coronary heart disease and systolic dysfunction, 12 months of treatment with the selective inhibitor of cyclic guanosine monophosphatespecific phosphodiesterase 5 (PDE-5) increased mean left ventricular ejection fraction and reduced left ventricular filling pressures without changes in coronary blood flow [64]. A multicenter trial is underway to determine if the PDE-5 inhibitor, Sildenafil, would improve exercise capacity and ventricular remodeling in heart failure with reduced ejection fraction [65]. Although both men and women are eligible for this trial, analysis of the resulting data by sex (rather than 
Fig. 1 Schematic of relationship between endothelial cells and nitric oxide $(N O)$ synthesis, as implicated in $\mathrm{HFpEF}$ pathophysiology. Pathways shown represent experimental evidence to date; avenues for future experimental investigation are indicated by question mark. Abbreviations: $N O$, nitric oxide; eNOS, NOS, nitric oxide synthase, eNOS, endothelial-derived nitric oxide synthase; $n N O S$, neuronal nitric oxide synthase; $\mathrm{BH} 4$, tetrahydrobiopterin (NOS cofactor); $\mathrm{O}_{2}^{-}{ }^{-}$, superoxide; HTN, hypertension. Modified from Fig. 3 of [13]

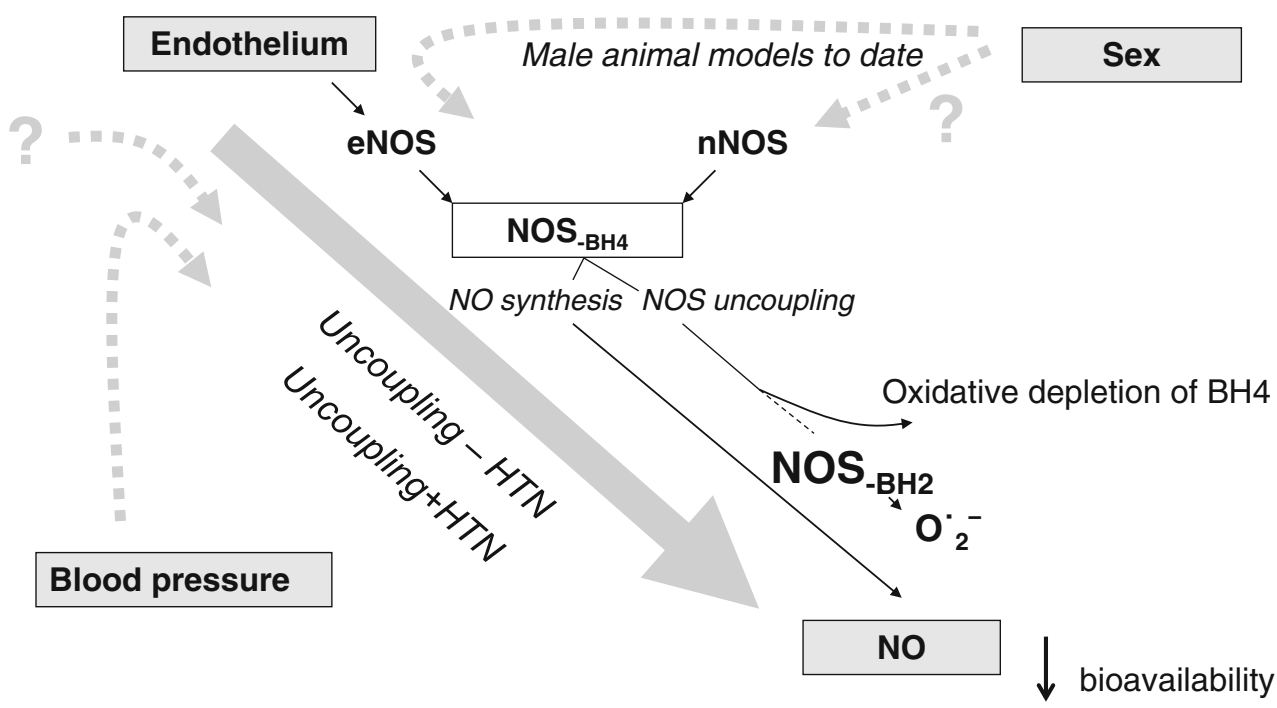

adjusting for sex) will be required to evaluate efficacy of this therapeutic approach in women with reduced ejection fraction.

Use of phosphodiesterase inhibitors has not proven to be effective in treatment of HFpEF. Brain-type natriuretic factor (BNP), which also increases intra-cellular cGMP, is elevated in heart failure $[66,67]$. Based on extensive experimental evidence derived from animal models of heart failure and small clinical studies suggesting that increases in cGMP might improve cardiac function, a multicenter trial (RELAX) was initiated to investigate effects of Sildenafil in patients with HFpEF [68]. However, results of this trial were disappointing in that there were no improvements in clinical status, exercise capacity, or ventricular remodeling in the treated group [69]. Although the trial consisted of about $50 \%$ men and women (most of whom were likely post-menopausal based on age), the results were not analyzed by sex and many had confounding conditions such as diabetes which might not have been modeled in pre-clinical mechanistic studies most of which were conducted in male animals. Although BNP levels vary by sex and decade of life [70], no studies have related levels of BNP to cardiac performance in female animals taking into account hormonal status.

Adrenergic activation is also blunted by increases in cGMP $[71,72]$. Effects of nitric oxide-like compounds including PDE-5 inhibitors, also could affect myocardial function indirectly through interactions with the sympathetic nervous system. These interactions have not been completely explored in mechanistic studies using male and female experimental material. Given the results of trials targeting PDE-5, there is a need for integrative studies of mechanisms involving $\mathrm{NO}$ and BNP that might differ between males and females of varying hormonal status to gain new insights into alternative therapeutic approaches [73].
Production of nitric oxide is modulated by sex steroid hormones [74]. In general, estrogen upregulates eNOS and increases bioavailability of nitric oxide [74]. However, in postmenopausal women with hypertension, effects of hormonal treatments on synthesis and bioavailability of nitric oxide may be confounded by other changes in regulatory systems that are refractory to reversible, activational effects of hormones [75-77] (Fig. 1). Effects of androgen stimulation on the NO/eNOS system are controversial [74] in part, due to the aromatization of testosterone to estrogen.

Metabolism of testosterone by aromatase within the myocardium can affect cardiac function. Although androgens have an anabolic effect on cardiac myocytes, estrogen will reduce calcium sensitivity and subsequently have a negative inotropic effect on cardiac function [78]. Polymorphisms in aromatase are associated with sex-specific outcomes for acute coronary syndrome. In men the CYP19A1 SNP $-81371 \mathrm{C}>\mathrm{T}$ associated with increased mortality; the opposite was found for women. In men with hypertension and coronary artery disease, this same SNP was associated with increased mortality, myocardial infarction, and stroke, again, the opposite was found for women carrying this genetic polymorphism [79]. Deficiencies in testosterone and other anabolic steroids are independent negative prognostic indicators of outcomes for men with systolic heart failure [80]. Contributions of changes in ratio of bioavailable androgens including testosterone to estrogen in development of hypertension and HFpEF in men and menopausal women need to be explored in more depth as clinical use of androgenic hormone treatments for men is increasing and their use in women remains controversial. Specific studies are needed to consider testosterone concentrations (free vs total) in relationship to aromatase activity on endothelial function, 
blood pressure, and other metabolic cardiovascular risk factors in both men and women.

\section{Renin-Angiotensin-Aldosterone System (RAAS)}

Chronic increases in blood pressure and blood volume activate RAAS. Activation of the RAAS is also associated with increased levels of TFG- $\beta$, in conjunction with the recruitment of smooth muscle cells, monocytes, and fibroblasts [81], stimulating a "genetic program of wound repair" [82]. This genetic program leads to increased deposition and decreased turnover of extracellular matrix in the heart and blood vessels and largely mirrors many of the profibrotic mechanisms detailed later. Ultimately, the parallel and convergence of RAAS activation and a profibrotic genetic program results in perivascular scarring and the amplification of organ damage resulting from hypertensive disease. In addition, as increased mechanical stretch is a stimulus for myocyte hypertrophy, with chronic RAAS activation, sustained increases in blood volume would provide such a stimulus for cardiomyocyte hypertrophy.

Sex differences in the RAAS have been reviewed recently [83]. In brief, estrogen upregulates angiotensinogen and it downregulates renin synthesis, activity of angiotensinconverting enzyme (ACE) and angiotensin 1 receptor signaling $[84,85]$. Despite being mechanistically characterized in vitro by well-defined experimental conditions, clinically relevant effects of estrogen on RAAS remain inconclusive [86-88]. Although angiotensin-converting enzyme inhibitors reduce blood pressure in women, they may cause some side effects such as coughing and may not reduce blood pressure to target goals in women as in men [3]. However, in the I-PRESERVE study of elderly patients with HFpEF, the angiotensin 11 receptor blocker Irbesartan reduced all cause mortality and heart failure hospitalization more in women than men [8].

Testosterone also contributes to activation of the RAAS. Basal ACE activity in the hypertensive rat (mRen(2) Lewis rat) is higher in males than females [89]. Castration of male rats reduced ACE activity, whereas testosterone treatment to ovariectomized female rats increased ACE activity [90] supporting a sex-independent, but reversible hormonal activational effect on the enzyme. Sexual dimorphisms in pro-renin levels have been observed in humans, with males having significantly higher levels of renin compared to women [91]. In a study of South African men and women, testosterone levels in both hypertensive males and females were significantly higher compared to normotensive study participants. Collectively, testosterone may increase the progression of hypertension to cardiac hypertrophy and subsequent heart failure through increased angiotensinogen and renin synthesis. Clinical benefit from angiotensin-converting enzyme inhibitors may be less in patients with HFpEF than in those with reduced ejection fraction [92, 93]. Further studies are required to determine how both testosterone and estrogens regulate expression of angiotensin receptors, their biodistribution with RAAS activation and inactivation of the RAAS with medications targeting angiotensin-converting enzymes in women in HFpEF and the relationship to chronic renal disease [73, 94-99].

Mineralocorticoids are activated during volume expansion. Aldosterone also affects development of arrhythmias, matrix deposition, and may also affect glycemic control [12]. As atrial fibrillation, obesity, and diabetes are also risk factors for HFpEF, mineralocorticoid receptor antagonists may be useful in treatment of HFpEF [100, 101]. However, additional studies are needed to evaluate sex-specific efficacy and effects of sex steroids on treatment outcomes.

\section{Extracellular Matrix}

Ventricular fibrosis characterized by fibroblast proliferation and deposition of the extracellular matrix ultimately leads to distortion of cardiac architecture and function. In the heart, fibrosis can result in ventricular stiffening with impairment of mechano-electric functions, ion-channel exchange, and cell signaling, leading to microvascular rarefation and subsequent diastolic dysfunction. Clinically, an impaired mechanoelectric coupling increases the risk of arrhythmia-associated cardiopathies, and marked atrial fibrosis associates with chronic heart disease [102-105].

Traditionally, it was thought that activated fibroblasts derive principally from resident fibroblast or from mesenchymal cells. However, profibrotic cells may derive from endothelial cells transformed to mesenchymal cells (EndoMT) [106]. These EndoMT in conjunction with the active recruitment of profibrotic cells to sites of activation exacerbate microvascular rarefication [107]. However, little is known regarding sex differences in differentiation of these types of cells.

Sex hormones affect cellular differentiation. 17 $\beta$-Estradiol limits cardiac fibroblast proliferation and differentiation and also suppresses DNA synthesis in neonatal cardiac fibroblasts $[102,105]$. Effects of testosterone on development of cardiac fibrosis are conflicting. Castration, in one study, significantly increased cardiomyocyte apoptosis and fibrosis suggesting that the removal of testosterone was deleterious to cardiac health [108]. Yet other studies suggest that androgens exacerbate cardiac fibrosis during aging [109], and excessive testosterone levels increase myocardial hypertrophy [110], structural alterations, and induce apoptosis. These discrepancies most likely reflect difference in experimental material (sex and hormonal status), genetic or chemically induced heart failure, or in vivo vs in vitro observations. Careful studies are 
needed that control for sex, hormonal status, and perhaps aromatase polymorphisms (see above) in order to resolve these discrepancies.

Sex steroid hormones modulate several enzymes and growth factors associated with EndoMT [111] and tissue remodeling including matrix metalloproteinases, transforming growth factor $\beta$ (TGF- $\beta$ ), angiotensin II (AngII), endothelin-1 (ET1), TNF- $\alpha$, fibronectin, and collagen. Progesterone and $17 \beta$-estradiol, alike, increase mRNA of TGF- $\beta$ and fibronectin. Conversely, $17 \beta$-estradiol mitigates the activation of AngII and ET1 stimulation, suppressing RAAS activation while reducing synthesis of mesenchymal proteins fibronectin, vimentin, and collagens I and III. Taken together, these observations support that estrogen, most likely through estrogen receptor- $\beta$ signaling, retards the development of cardiac fibrosis and hypertrophy - both of cardiomyocytes, and on a larger scale, structure, and thus function of the heart $[112,113]$. Serum monitoring of matrix metalloproteinase 9 (MMP9) and tissue inhibitor of metalloproteinase 1 (TIMP1) may serve as potential biomarkers to assess risk for development of HFpEF. In a crossover study, the ratio of MMP9/TIMP1 correlated with the degree of diastolic dysfunction using a logistic regression model adjusted for age, sex, systolic blood pressure, and creatinine [114]. Although this study consisted of about $50 \%$ men and women, data were not dichotomized by sex to determine if there were sex-specific ranges and it is unclear how these enzymes might be regulated or elevated in women with a history of hypertensive pregnancy disorders. Such information is needed if therapies targeting these enzymatic pathways are to be developed.

\section{Modalities to Assess Sex Differences in Cardiac Function}

Despite macroscopic anatomic similarities in hearts of males and females, there are sex differences in microarchitecture which affect cardiac function in response to increasing age and hormonal status and hypertension. Computed tomography, magnetic resonance imaging (MRI), and echocardiography are used in clinical assessment of left

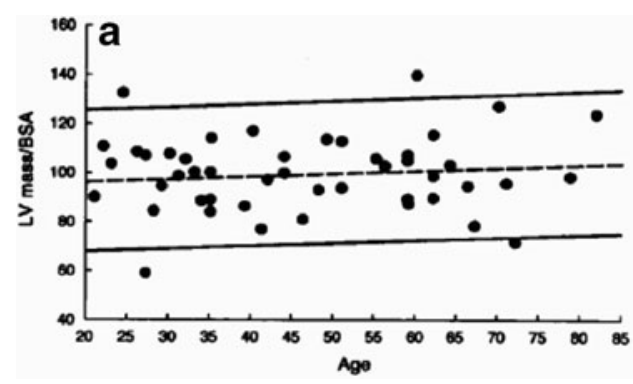

Fig. 2 Left ventricular mass determined by echocardiography normalized to height in healthy men (a) and women (b) by decade of life. Dashed lines are mean values; solid lines are $95 \%$ confidence ventricular size, function, and mass to describe cardiac anatomy and function for diagnosis of cardiovascular diseases. However, few studies have defined sex-specific reference values for left ventricular function using these imaging modalities.

Using echocardiography, left ventricular mass did not increase with age in men but did so in women even when indexed to body surface area (Fig. 2) [115-119]. In the Framingham study, after the age of 60 , the prevalence of left ventricular hypertrophy in females increased by $69 \%$ per decade of life compared to $15 \%$ in males [120]. The disparity in left ventricular remodeling is particularly marked in pressure overload states such as hypertension [33]. For example, sex differences have been identified using 2-D and M-mode echocardiographic techniques in cardiac structure and function with hypertension and its treatments [121, 122]. The left ventricle of hypertensive females showed greater fractional shortening, smaller end diastolic chamber size, and higher ejection fraction than males. An eccentric pattern of remodeling was more common in males while a concentric pattern of remodeling was common in females [123, 124]. With long-term antihypertensive treatment, hypertensive women retained higher left ventricular ejection fraction, and stresscorrected mid-wall shortening in spite of less hypertrophy regression compared to men [121]. These results suggest sex differences in cardiac structure and function with hypertension resulting from the mechanisms discussed in the previous sections.

3D echocardiography combined with 3D color Doppler provides improved accuracy and reproducibility over 2D methods for left ventricular volume and function calculations and is an efficient tool for assessing systolic and diastolic dysfunction for diagnosing heart failure [125]. An estimate of the chamber stiffness can be obtained indirectly using the pressure-volume relationships where the stiffness is the slope of the tangent drawn to the curve [126-128]. However, direct imaging of elastic properties of the heart would move this field forward and allow for better identification of sex-specific changes in myocardial stiffness.

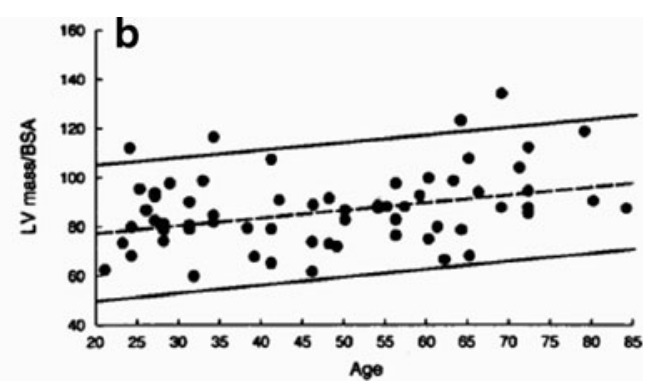

intervals. Left ventricular mass did not increase with age in men $(p=0.73)$ but did so in women $(p=0.03)$. Reprinted with permission from Fig. 2 of reference [141] 
Fig. 3 An example of using magnetic resonance elastography to estimate myocardial contractility in a sexually immature pig. $a-d$ represent the end-systolic short axis image of the left ventricle; $f-i$ represent the end-systolic short axis after infusion of epinephrine. The green and orange contours delineate the myocardium. $e$ (baseline) and $j$ (after infusion) are maps of stiffness. Reproduced with permission from Fig. 3 of reference [142]

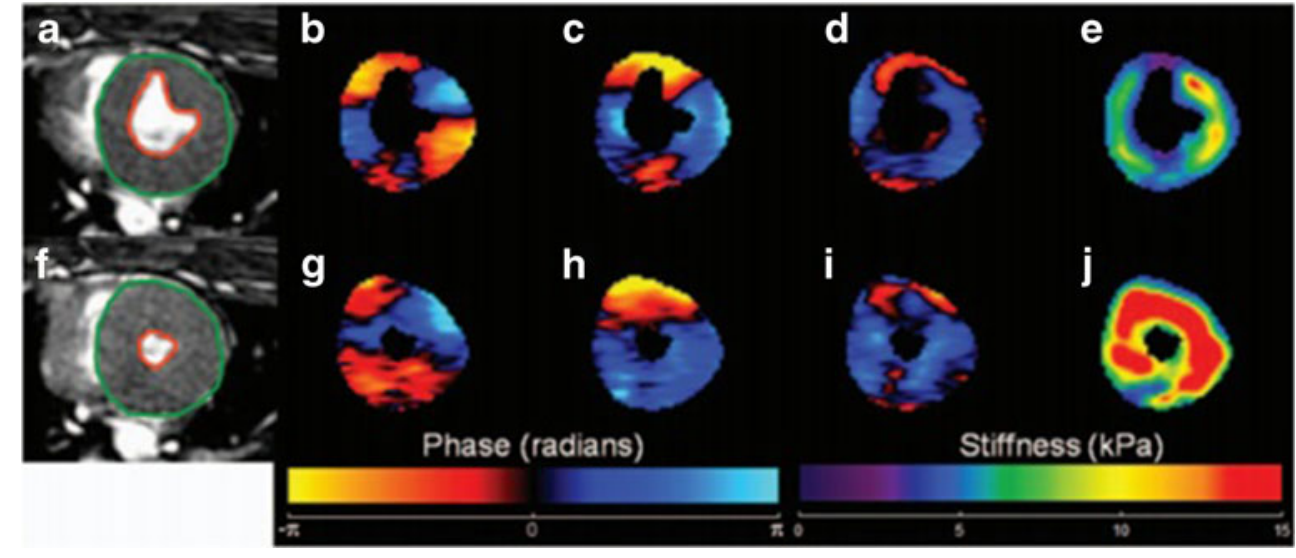

Intrinsic mechanical properties of tissues (i.e., stiffness) can be obtained by applying a mechanical excitation or stress to tissues and measuring the resulting tissue deformation in response to that stress based on stress-strain relationships or models of shear wave propagation. One such method, acoustic radiation force imaging (ARFI), measures tissue responses by using radiation force from long pulses to impart localized displacement of the propagating shear waves. Application of this technique throughout the cardiac cycle may be useful in providing insight into sex differences in myocardial performance [129]. Another technique, shear wave imaging (SWI) includes imaging the shear wave propagation at an ultrahigh frame rate $(12,000 \mathrm{images} / \mathrm{s})$ using the same diagnostic probe connected to an ultrafast ultrasonic device [130].

Cardiac magnetic resonance elastography (CMRE) is a noninvasive MRI-based phase contrast technique for quantitative assessment of myocardial stiffness where propagating shear waves are imaged and tissue stiffness is derived [131]. A fully functional CMRE demands fast 3D imaging sequences and robust 3D inversion algorithms for obtaining stiffness maps from the 3D displacements obtained from the propagating shear waves. Using this technique, differences in stiffness were reported in one of five pigs (four males and one female) in response to an epinephrine challenge (Fig. 3). However, it is unknown if differences were observed in the female compared to the male pigs. Given the weight of the animals, it is unlikely that the pigs had reached sexual maturity and it is unknown if the males had been castrated at birth. Such information regarding sex and hormonal status is critical in order to assess influence of sex from changes in hormonal status with aging.

Modalities to image elasticity face serious technical challenges due to the complex 3D geometry and anisotropy
Fig. 4 Diagram depicting where future research is needed to include sex and hormonal status into integrative physiologic studies of HFpEF. Abbreviation: $R A A S$ - renin angiotensin/ aldosterone system

\section{Integration of sex and hormonal status into physiological studies of HFpEF}

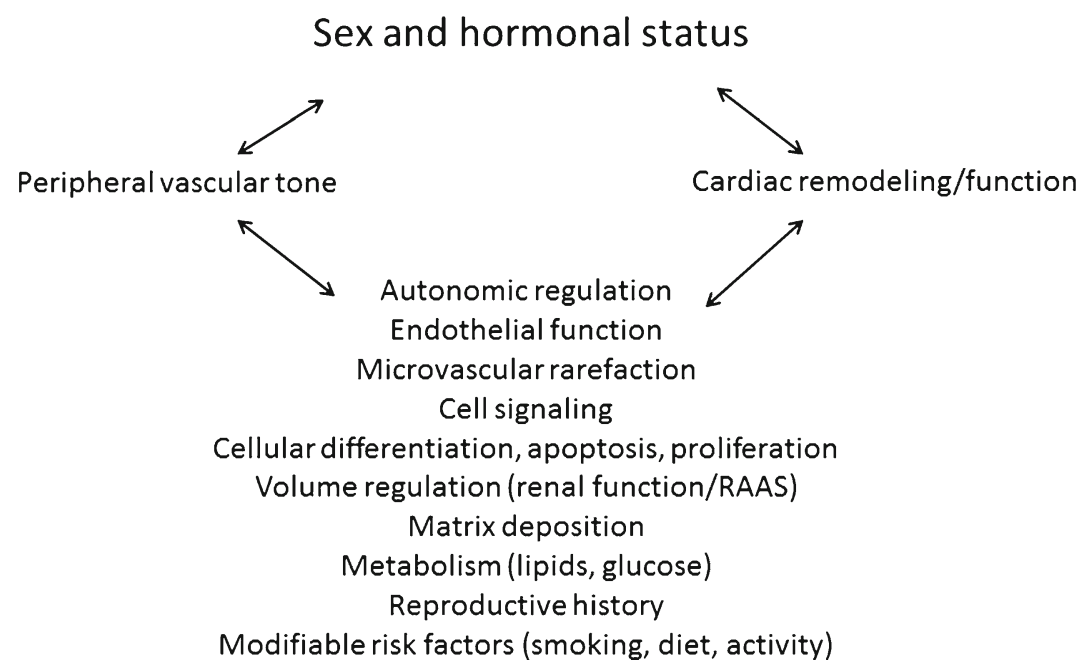




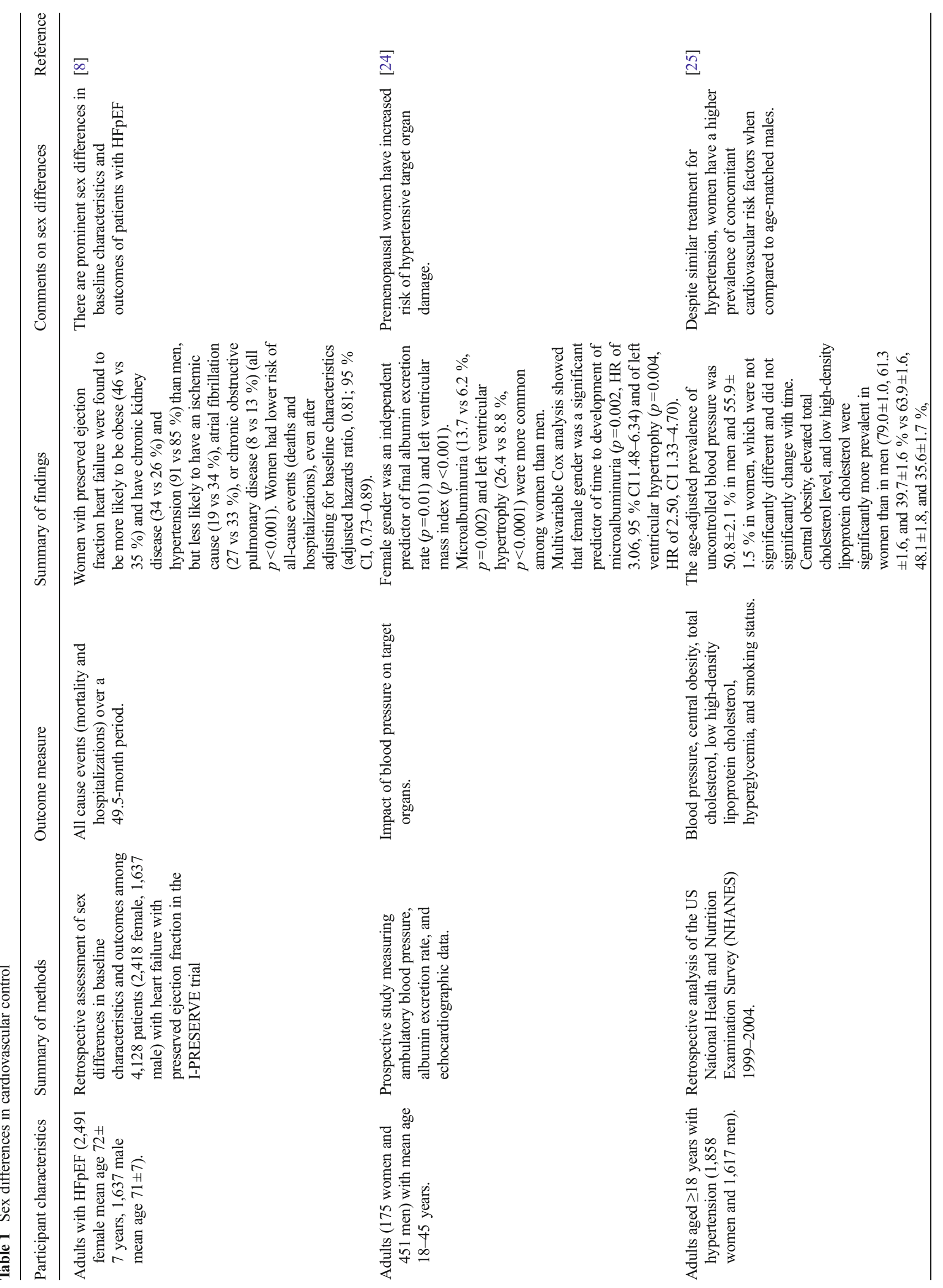




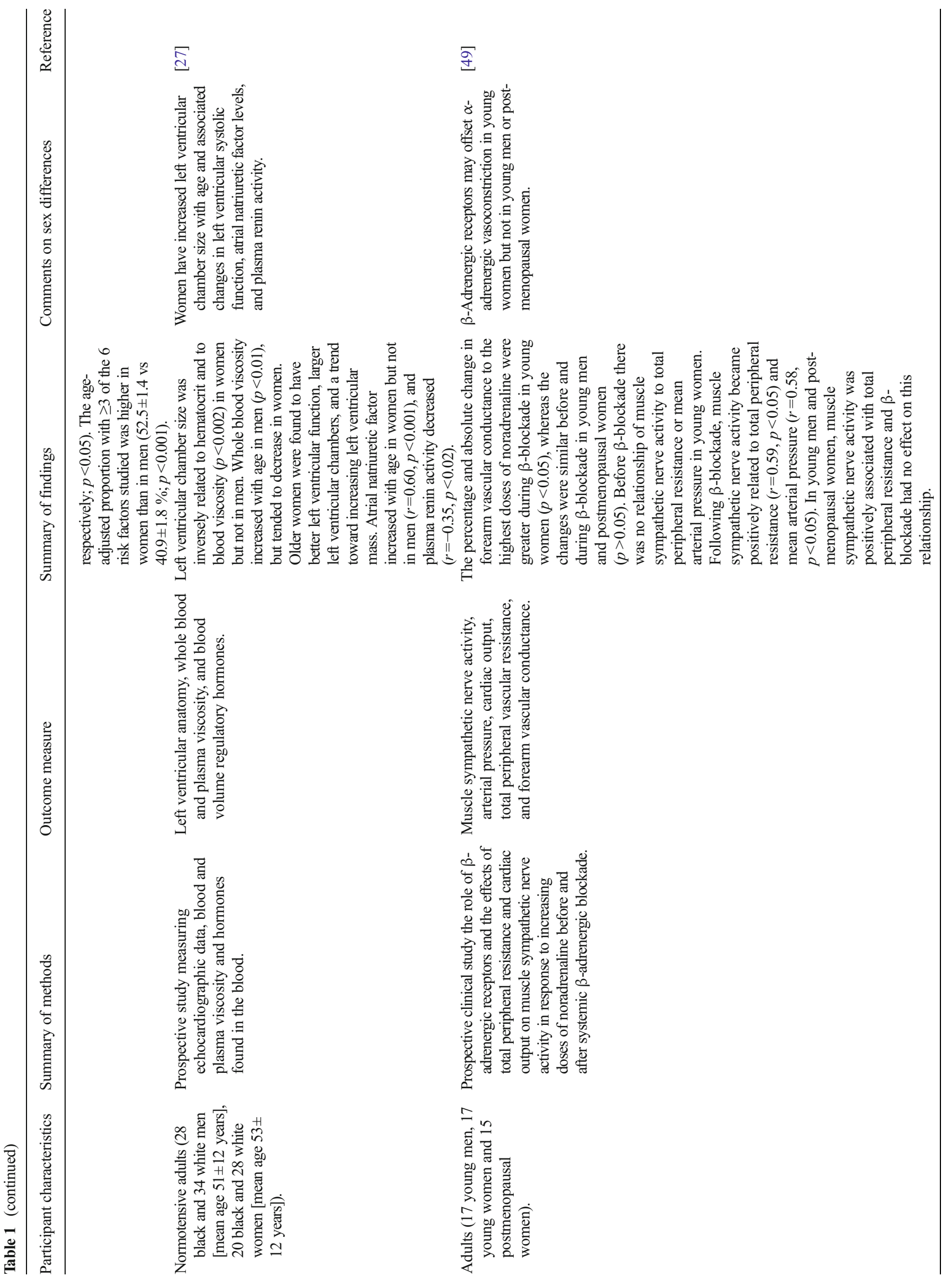




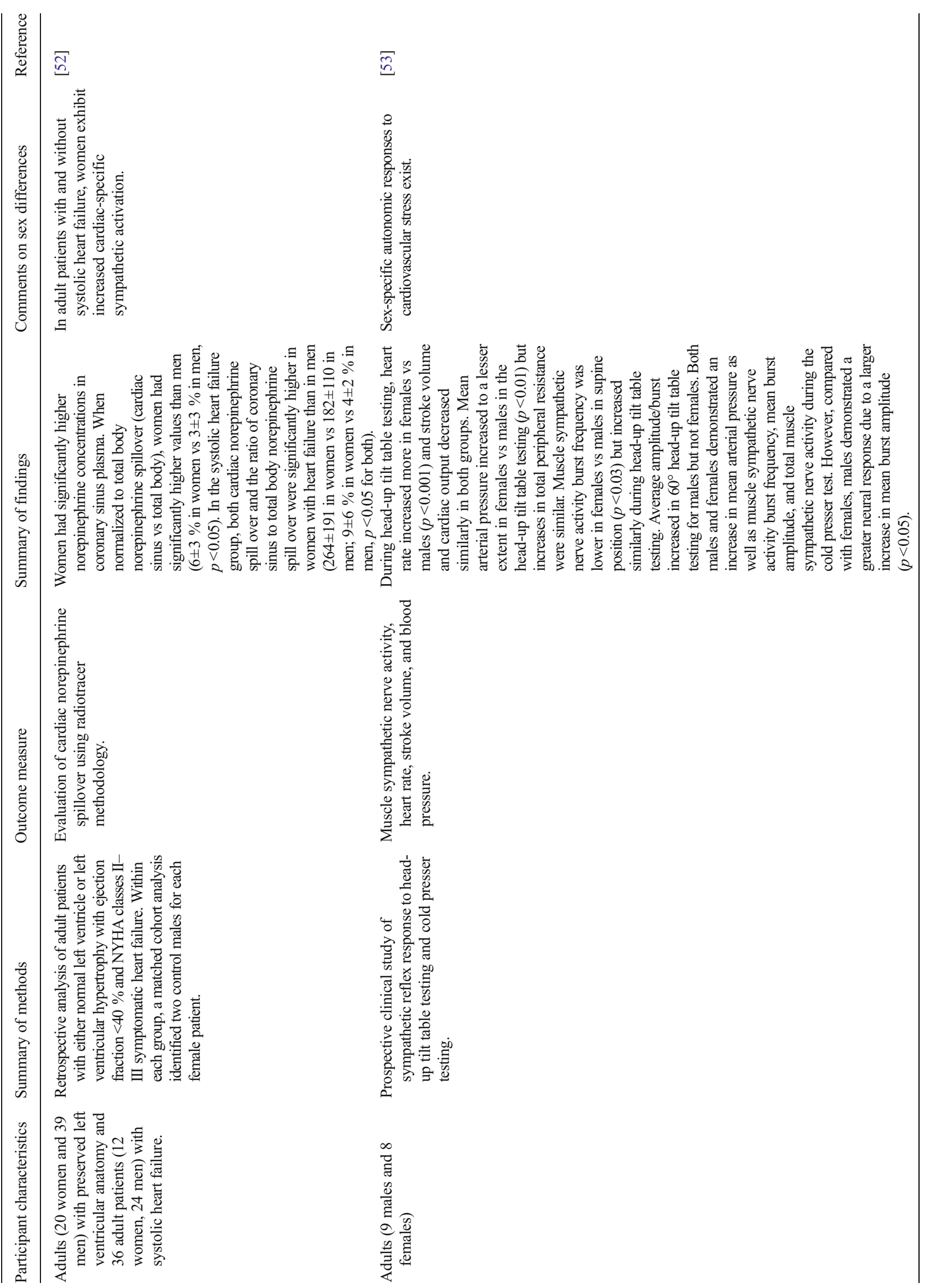




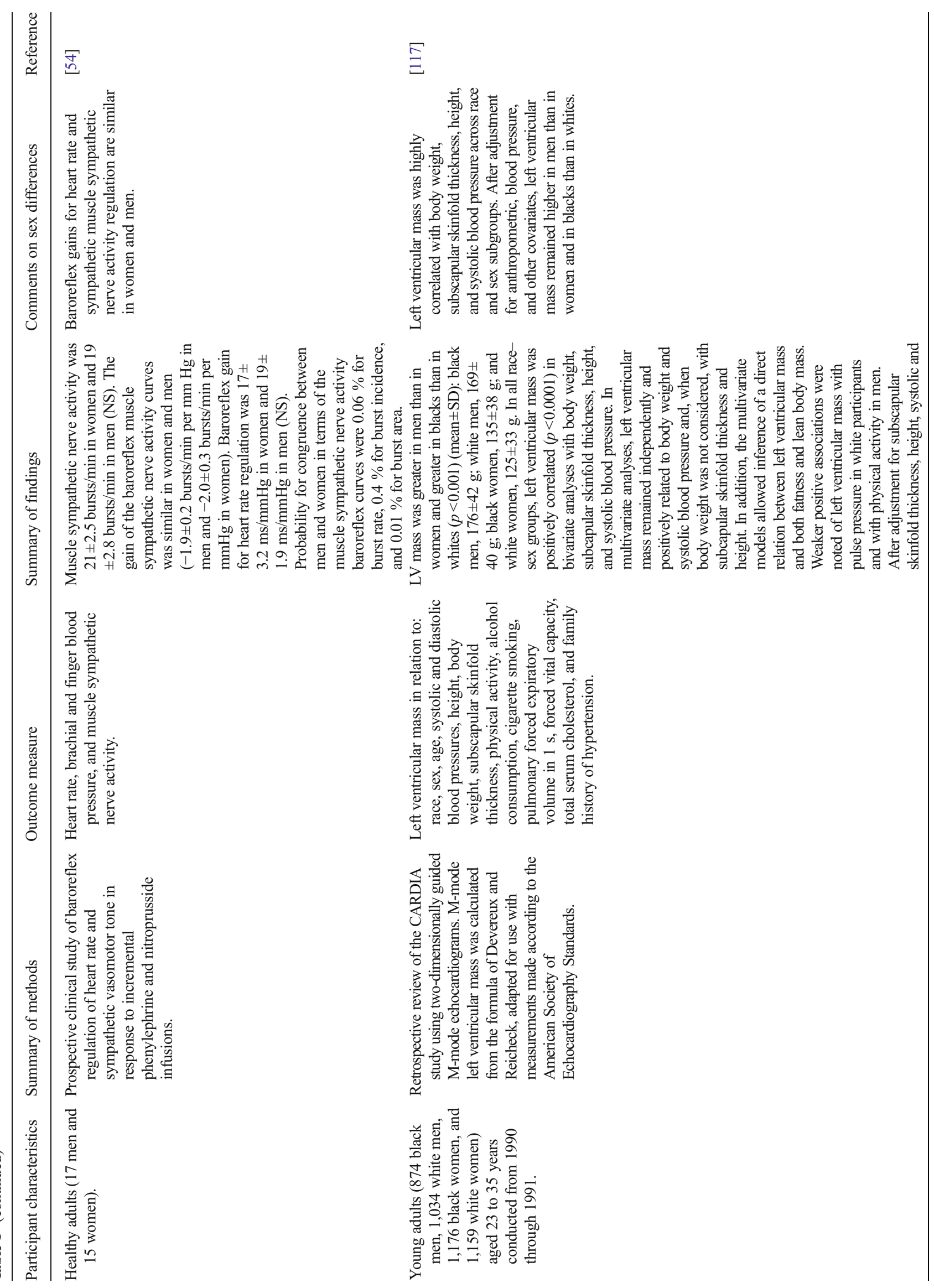


of the heart. However, upon successful resolution of these challenges, data on sex-specific changes in myocardial elasticity will open new avenues for differentiating effects of chromosomal sex from activational and organizational effects of the sex steroids on cardiac stiffness. Such information is critical in order to develop sex-specific criteria for diagnosis and prognosis for treatments of HFpEF.

Moving Forward

Attention of the scientific community has been directed toward the inability to reproduce many basic science experiments and to translate their results to the clinical arena [132]. Potential solutions have been proposed, most of which have focused on experimental design and statistical analysis (go.nature.com/ oloeip). Some of the difficulty with reproducing experimental results across laboratories derives from the lack of reporting the sex of experimental material $[6,133]$. In addition, in order to understand mechanistic pathways of physiological processes, the sex of the cells/animals must be identified and some information is needed regarding the hormonal status of the donor material to control for organizational effects of sex steroid hormones [134]. Studies of genetic variants (knock-in and knock-out) in animals must include both males and females as gene expression in most tissues varies by sex [135-137]. Much is to be learned regarding why one sex may exhibit a phenotype while the other may be protected. However, analyzing the data from mixed groups of males and females may mask an effect especially if the particular response may be upregulated in one sex and downregulated in the other. Funding agencies should be more diligent in requiring appropriate scientific justification for studying only male animals beyond avoiding increased variability of data or hormonal variations that are characteristics of adult females [138]. Experimental design to account for hormonal variations can be developed. Although including female animals into the experimental design may increase initial costs, this investment will be balanced by the cost and time wasted by developing a therapeutic approach based on one sex that fails clinical testing due to adverse events in a mixed study population of men and women [139, 140].

\section{Conclusion}

Sex differences in the regulation of the cardiovascular system reflect the influence of the sex chromosomes and sex steroid hormones. Sex-specific risks for development of hypertension and type and severity of heart failure reflect the interactions of these influences. Shifts in circulating concentrations of sex steroids that accompany pregnancy and menopause in women affect autonomic and endothelial regulation of vascular tone, vasoactive cytokines, and hormones of the renninangiotensin-aldosterone system (Fig. 4). Collectively, these 
changes will affect the risk, onset, and severity of hypertension and functional and structural characteristics of the heart leading to heart failure (Table 1). In order to improve diagnosis and treatment for men and women with heart failure, mechanistic studies of cellular contributions to cardiovascular control need to be explored in female animals and in women of known hormonal status. In addition, imaging modalities must be developed to detect changes in elasticity and performance of the heart both as a tool to understand mechanistic integration of cardiac function and for diagnostic and prognostic purposes. Understanding of myocardial remodeling affecting function continues to evolve. Focusing attention on sex differences in development of chronic diseases may result in sex-specific diagnostic and treatment modalities which could improve outcomes and reduce disparities in sex differences in mortality from these diseases.

Acknowledgments This work was funded in part by grants from the National Institute of Aging P50 AG44170 and the Mayo Foundation.

Open Access This article is distributed under the terms of the Creative Commons Attribution License which permits any use, distribution, and reproduction in any medium, provided the original author(s) and the source are credited.

\section{References}

1. Roger, V. L., Go, A. S., Lloyd-Jones, D. M., Benjamin, E. J., Berry, J. D., Borden, W. B., et al. (2012). Heart Disease and Stroke Statistics-2012 update: a report from the American Heart Association. Circulation, 125, e2-e220.

2. Go, A. S., Mozaffarian, D., Roger, V. L., Benjamin, E. J., Berry, J. D., Borden, W. B., et al. (2013). Heart disease and stroke statistics2013 update: a report from the American Heart Association. Circulation, 127, e6-e245. doi:10.1161/CIR.0b013e31828124ad.

3. Mosca, L., Benjamin, E. J., Berra, K., Bezanson, J. L., Dolor, R. J., Lloyd-Jones, D. M., et al. (2011). Effectiveness-based guidelines for the prevention of cardiovascular disease in women - 2011 Update: a guideline from the American Heart Association. Circulation, 123, 1243-1262. doi:10.1161/CIR.0b013e31820faaf8.

4. Seeland, U., \& Regitz-Zagrosek, V. (2012). Sex and gender differences in cardiovascular drug therapy. Handbook of experimental pharmacology, 214, 211-236. doi:10.1007/978-3.

5. Zucker, I., \& Beery, A. K. (2010). Males still dominate animal studies. Nature, 465, 690. doi:10.1038/465690a.

6. Taylor, K. E., Vallejo-Giraldo, C., Schaible, N. S., Zakeri, R., \& Miller, V. M. (2011). Reporting of sex as a variable in cardiovascular studies using cultured cells. Biology of Sex Differences, 2, 11.

7. Melloni, C., Berger, J. S., Wang, T. Y., Gunes, F., Stebbins, A., Pieper, K. S., et al. (2010). Representation of women in randomized clinical trials of cardiovascular disease prevention. Circulation. Cardiovascular Quality and Outcomes, 3, 135-142. doi:10.1161/ CIRCOUTCOMES.110.868307.

8. Lam, C. S., Carson, P. E., Anand, I. S., Rector, T. S., Kuskowski, M., Komajda, M., et al. (2012). Sex differences in clinical characteristics and outcomes in elderly patients with heart failure and preserved ejection fraction: the Irbesartan in Heart Failure with Preserved Ejection Fraction (I-PRESERVE) trial. Circulation.
Heart Failure, 5, 571-578. doi:10.1161/CIRCHEARTFAILURE. 112.970061.

9. Regitz-Zagrosek, V., \& Lehmkuhl, E. (2005). Heart failure and its treatment in women. Role of hypertension, diabetes, and estrogen. Herz, 30, 356-367.

10. Owan, T. E., Hodge, D. O., Herges, R. M., Jacobsen, S. J., Roger, V. L., \& Redfield, M. M. (2006). Trends in prevalence and outcome of heart failure with preserved ejection fraction. New England Journal of Medicine, 355, 251-259. doi:10.1056/NEJMoa052256.

11. Bhatia, R. S., Tu, J. V., Lee, D. S., Austin, P. C., Fang, J., Haouzi, A., et al. (2006). Outcome of heart failure with preserved ejection fraction in a population-based study. New England Journal of Medicine, 355, 260-269. doi:10.1056/NEJMoa051530.

12. Zouein, F. A., de Castro Bras, L. E., da Costa, D. V., Lindsey, M. L., Kurdi, M., \& Booz, G. W. (2013). Heart failure with preserved ejection fraction: emerging drug strategies. Journal of Cardiovascular Pharmacology, 62, 13-21. doi:10.1097/FJC. 0b013e31829a4e61.

13. Zakeri R, Vallejo-Giraldo C, Taylor KE, Miller VM, Schaible NS (2011) Using heart failure with preserved ejection fraction to understand an 'omics approach to evaluating vascular dysfunction and cardiovascular disease. Journal of Neurology and Neurophysiology S1-006. doi:10.4172/2155-9562.S1-006

14. Charchar, F. J., Tomaszewski, M., Lacka, B., Zakrzewski, J., Zukowska-Szczechowska, E., Grzeszczak, W., et al. (2004). Association of the human Y chromosome with cholesterol levels in the general population. Arteriosclerosis, Thrombosis, and Vascular Biology, 24, 308-312. doi:10.1161/01.ATV.0000113291. 39267.0a.

15. Charchar, F. J., Bloomer, L. D., Barnes, T. A., Cowley, M. J., Nelson, C. P., Wang, Y., et al. (2012). Inheritance of coronary artery disease in men: an analysis of the role of the $\mathrm{Y}$ chromosome. Lancet, 379, 915-922. doi:10.1016/S0140-6736(11)61453-0.

16. Bloomer, L. D., Nelson, C. P., Eales, J., Denniff, M., Christofidou, P., Debiec, R., et al. (2013). Male-specific region of the Y chromosome and cardiovascular risk: phylogenetic analysis and gene expression studies. Arteriosclerosis, Thrombosis, and Vascular Biology, 33, 1722-1727. doi:10.1161/ATVBAHA.113.301608.

17. Avner, P., \& Heard, E. (2001). X-chromosome inactivation: counting, choice and initiation. Nature Reviews Genetics, 2, 59-67.

18. Miller, V. M., Kaplan, J. R., Schork, N. J., Ouyang, P., Berga, S. L., Wenger, N. K., et al. (2011). Strategies and methods to study sex differences in cardiovascular structure and function: a guide for basic scientists. Biology of Sex Differences, 2, 14. doi:10.1186/ 2042-6410-2-14.

19. Hayward, C. S., Kelly, R. P., \& Collins, P. (2000). The roles of gender, the menopause and hormone replacement on cardiovascular function. Cardiovascular Research, 46, 28-49.

20. Wiinberg, N., Hoegholm, A., Christensen, H. R., Bang, L. E., Mikkelsen, K. L., Nielsen, P. E., et al. (1995). 24-h ambulatory blood pressure in 352 normal Danish subjects, related to age and gender. American Journal of Hypertension, 8, 978-986.

21. Iseki, K., Kimura, Y., Wakugami, K., Okumura, K., Muratani, H., Ikemiya, Y., et al. (2000). Comparison of the effect of blood pressure on the development of stroke, acute myocardial infarction, and end-stage renal disease. Hypertension Research, 23, 143-149.

22. Staessen, J., Guo, C., De Cort, P., Fagard, R., Lijnen, P., Thijs, L., et al. (1992). Mean and range of the ambulatory pressure in normotensive subjects. Chinese Medical Journal, 105, 328-333.

23. Staessen, J., Fagard, R., Lijnen, P., Thijs, L., van Hoof, R., \& Amery, A. (1990). Reference values for ambulatory blood pressure: a meta-analysis. Journal of Hypertension. Supplement, 8, S57-S64.

24. Palatini, P., Mos, L., Santonastaso, M., Saladini, F., Benetti, E., Mormino, P., et al. (2011). Premenopausal women have increased risk of hypertensive target organ damage compared with men of 
similar age. Journal of Women's Health, 20, 1175-1181. doi:10. 1089/jwh.2011.2771.

25. Ong, K. L., Tso, A. W., Lam, K. S., \& Cheung, B. M. (2008). Gender difference in blood pressure control and cardiovascular risk factors in Americans with diagnosed hypertension. Hypertension, 51, 1142-1148. doi:10.1161/ HYPERTENSIONAHA.107.105205.

26. Ong, K. L., Cheung, B. M., Man, Y. B., Lau, C. P., \& Lam, K. S. (2007). Prevalence, awareness, treatment, and control of hypertension among United States adults 1999-2004. Hypertension, 49, 69-75. doi:10.1161/01.HYP.0000252676. 46043.18.

27. de Simone, G., Devereux, R. B., Roman, M. J., Ganau, A., Chien, S., Alderman, M. H., et al. (1991). Gender differences in left ventricular anatomy, blood viscosity and volume regulatory hormones in normal adults. The American Journal of Cardiology, 68, 1704-1708.

28. Papadopoulos, D. P., \& Papademetriou, V. (2010). Hypertrophic and hypertensive hypertrophic cardiomyopathy-a true association? Angiology, 61, 92-99. doi:10.1177/0003319709331391.

29. Topol, E. J., Traill, T. A., \& Fortuin, N. J. (1985). Hypertensive hypertrophic cardiomyopathy of the elderly. New England Journal of Medicine, 312, 277-283. doi:10.1056/NEJM198501313120504.

30. Pearson, A. C., Gudipati, C. V., \& Labovitz, A. J. (1988). Systolic and diastolic flow abnormalities in elderly patients with hypertensive hypertrophic cardiomyopathy. Journal of the American College of Cardiology, 12, 989-995.

31. Lewis, J. F., \& Maron, B. J. (1994). Clinical and morphologic expression of hypertrophic cardiomyopathy in patients $\geq 65$ years of age. The American Journal of Cardiology, 73, 1105-1111.

32. Lewis, J. F., \& Maron, B. J. (1990). Diversity of patterns of hypertrophy in patients with systemic hypertension and marked left ventricular wall thickening. The American Journal of Cardiology, $65,874-881$

33. Devereux, R. B., Casale, P. N., Hammond, I. W., Savage, D. D., Alderman, M. H., Campo, E., et al. (1987). Echocardiographic detection of pressure-overload left ventricular hypertrophy: effect of criteria and patient population. Journal of Clinical Hypertension, $3,66-78$.

34. Garovic, V., Bailey, K., Boerwinkle, E., Hunt, S., Weder, A., Curb, J., et al. (2010). Hypertension in pregnancy as a risk factor for cardiovascular disease later in life. Journal of Hypertension, 28 , 826-833.

35. Roberts, J. M., \& Hubel, C. A. (2010). Pregnancy: a screening test for later life cardiovascular disease. Women's Health Issues, 20, 304-307.

36. Safar, M. E., London, G. M., Asmar, R., \& Frohlich, E. D. (1998). Recent advances on large arteries in hypertension. Hypertension, $32,156-161$.

37. Izzo, J. L., Jr. (2004). Arterial stiffness and the systolic hypertension syndrome. Current Opinion in Cardiology, 19, 341-352.

38. Kass, D. A. (2005). Ventricular arterial stiffening: integrating the pathophysiology. Hypertension, 46, 185-193. doi:10.1161/01. HYP.0000168053.34306.d4.

39. Nichols, W. W. (2005). Clinical measurement of arterial stiffness obtained from noninvasive pressure waveforms. American Journal of Hypertension, 18, 3S-10S. doi:10.1016/j.amjhyper.2004.10.009.

40. Ely, D., Milsted, A., Bertram, J., Ciotti, M., Dunphy, G., \& Turner, M. E. (2007). Sry delivery to the adrenal medulla increases blood pressure and adrenal medullary tyrosine hydroxylase of normotensive WKY rats. BMC Cardiovascular Disorders, 7 , 6.

41. Ely, D., Milsted, A., Dunphy, G., Boehme, S., Dunmire, J., Hart, M., et al. (2009). Delivery of sry1, but not sry2, to the kidney increases blood pressure and sns indices in normotensive wky rats. $B M C$ Physiology, 9, 10. doi:10.1186/1472-6793-9-10.
42. Herbison, A. E., Simonian, S. X., Thanky, N. R., \& Bicknell, R. J. (2000). Oestrogen modulation of noradrenaline neurotransmission. Novartis Foundation Symposium, 230, 74-85. discussion 85-93.

43. Ivanova, T., \& Beyer, C. (2003). Estrogen regulates tyrosine hydroxylase expression in the neonate mouse midbrain. Journal of Neurobiology, 54, 638-647.

44. Pendergast, J. S., Tuesta, L. M., \& Bethea, J. R. (2008). Oestrogen receptor beta contributes to the transient sex difference in tyrosine hydroxylase expression in the mouse locus coeruleus. Journal of Neuroendocrinology, 20, 1155-1164.

45. Anglin, J. C., \& Brooks, V. L. (2003). Tyrosine hydroxylase and norepinephrine transporter in sympathetic ganglia of female rats vary with reproductive state. Autonomic Neuroscience, 105, 8 15 .

46. Lloyd, T., \& Weisz, J. (1978). Direct inhibition of tyrosine hydroxylase activity by catechol estrogens. The Journal of Biological Chemistry, 253, 4841-4843.

47. Charkoudian, N., Joyner, M. J., Johnson, C. P., Eisenach, J. H., Dietz, N. M., \& Wallin, B. G. (2005). Balance between cardiac output and sympathetic nerve activity in resting humans: role in arterial pressure regulation. The Journal of Physiology, 568, 315321. doi:10.1113/jphysiol.2005.090076.

48. Hart, E. C., Joyner, M. J., Wallin, B. G., Johnson, C. P., Curry, T. B., Eisenach, J. H., et al. (2009). Age-related differences in the sympathetic-hemodynamic balance in men. Hypertension, 54, 127-133. doi:10.1161/HYPERTENSIONAHA.109.131417.

49. Hart, E. C., Charkoudian, N., Wallin, B. G., Curry, T. B., Eisenach, J., \& Joyner, M. J. (2011). Sex and ageing differences in resting arterial pressure regulation: the role of the beta-adrenergic receptors. The Journal of Physiology, 589, 5285-5297. doi:10.1113/jphysiol. 2011.212753.

50. Mercuro, G., Podda, A., Pitzalis, L., Zoncu, S., Mascia, M., Melis, G. B., et al. (2000). Evidence of a role of endogenous estrogen in the modulation of autonomic nervous system. The American Journal of Cardiology, 85(787-789), A789.

51. Gianaros, P. J., Salomon, K., Zhou, F., Owens, J. F., Edmundowicz, D., Kuller, L. H., et al. (2005). A greater reduction in highfrequency heart rate variability to a psychological stressor is associated with subclinical coronary and aortic calcification in postmenopausal women. Psychosomatic Medicine, 67, 553-560.

52. Mitoff, P. R., Gam, D., Ivanov, J., Al-hesayen, A., Azevedo, E. R., Newton, G. E., et al. (2011). Cardiac-specific sympathetic activation in men and women with and without heart failure. Heart, 97, 382387. doi:10.1136/hrt.2010.199760.

53. Shoemaker, J. K., Hogeman, C. S., Khan, M., Kimmerly, D. S., \& Sinoway, L. I. (2001). Gender affects sympathetic and hemodynamic response to postural stress. American Journal of Physiology - Heart and Circulatory Physiology, 281, H2028-H2035.

54. Tank, J., Diedrich, A., Szczech, E., Luft, F. C., \& Jordan, J. (2005). Baroreflex regulation of heart rate and sympathetic vasomotor tone in women and men. Hypertension, 45, 1159-1164.

55. Fu, Q., Okazaki, K., Shibata, S., Shook, R. P., VanGunday, T. B., Galbreath, M. M., et al. (2009). Menstrual cycle effects on sympathetic neural responses to upright tilt. The Journal of Physiology, 587, 2019-2031.

56. Barnes, J. N., Matzek, L. J., Charkoudian, N., Joyner, M. J., Curry, T. B., \& Hart, E. C. (2012). Association of cardiac baroreflex sensitivity with blood pressure transients: influence of sex and menopausal status. Frontiers in Physiology, 3, 187. doi:10.3389/ fphys.2012.00187.

57. Brooks, V. L., Cassaglia, P. A., Zhao, D., \& Goldman, R. K. (2012). Baroreflex function in females: changes with the reproductive cycle and pregnancy. Gender Medicine, 9, 61-67. doi:10.1016/j.genm. 2012.02.004.

58. Miller, V. M., Garovic, V. D., Kantarci, K., Barnes, J. N., Jayachandran, M., Mielke, M. M., et al. (2013). Sex-specific risk 
of cardiovascular disease and cognitive decline: pregnancy and menopause. Biology of Sex Differences, 4, 6. doi:10.1186/20426410-4-6.

59. Garovic, V. D., \& August, P. (2013). Preeclampsia and the future risk of hypertension: the pregnant evidence. Current Hypertension Reports, 15, 114-121. doi:10.1007/s11906-013-0329-4.

60. Miller, V. M., \& Duckles, S. P. (2008). Vascular actions of estrogens: functional implications. Pharmacological Reviews, 60, 210-241.

61. Searles, C. D. (2006). Transcriptional and posttranscriptional regulation of endothelial nitric oxide synthase expression. American Journal of Physiology-Cellular Physiology, 291, C803-C816. doi:10.1152/ajpcell.00457.2005.

62. Paulus, W. J., \& Bronzwaer, J. G. (2004). Nitric oxide's role in the heart: control of beating or breathing? American Journal of Physiology - Heart and Circulatory Physiology, 287, H8-H13. doi:10.1152/ajpheart.01147.2003.

63. van Heerebeek, L., Franssen, C. P., Hamdani, N., Verheugt, F. W., Somsen, G. A., \& Paulus, W. J. (2012). Molecular and cellular basis for diastolic dysfunction. Current Heart Failure Reports, 9, 293 302. doi:10.1007/s11897-012-0109-5.

64. Guazzi, M., Vicenzi, M., Arena, R., \& Guazzi, M. D. (2011). PDE5 inhibition with sildenafil improves left ventricular diastolic function, cardiac geometry, and clinical status in patients with stable systolic heart failure: results of a 1-year, prospective, randomized, placebo-controlled study. Circulation. Heart Failure, 4, 8-17. doi: 10.1161/CIRCHEARTFAILURE.110.944694.

65. Cooper, T. J., Guazzi, M., Al-Mohammad, A., Amir, O., Bengal, T., Cleland, J. G., et al. (2013). Sildenafil in Heart failure (SilHF). An investigator-initiated multinational randomized controlled clinical trial: rationale and design. European Journal of Heart Failure, 15, 119-122. doi:10.1093/eurjhf/hfs152.

66. Hart, C. Y. T., Hahn, E. L., Meyer, D. M., Burnett, J. C., Jr., \& Redfield, M. M. (2001). Differential effects of natriuretic peptides and $\mathrm{NO}$ on LV function in heart failure and normal dogs. American Journal of Physiology-Heart and Circulatory Physiology, 281, H146-H154.

67. Managala, V. K., Burnett, J. C., Jr., \& Redfield, M. M. (2004). The natriuretic peptides in cardiovascular medicine. Current Problems in Cardiology, 29, 707-769.

68. Redfield, M. M., Borlaug, B. A., Lewis, G. D., Mohammed, S. F., Semigran, M. J., Lewinter, M. M., et al. (2012). PhosphdiesteRasE5 Inhibition to Improve CLinical Status and EXercise Capacity in Diastolic Heart Failure (RELAX) trial: rationale and design. Circulation. Heart Failure, 5, 653-659. doi:10.1161/ CIRCHEARTFAILURE.112.969071.

69. Redfield, M. M., Chen, H. H., Borlaug, B. A., Semigran, M. J., Lee, K. L., Lewis, G., et al. (2013). Effect of phosphodiesterase-5 inhibition on exercise capacity and clinical status in heart failure with preserved ejection fraction: a randomized clinical trial. JAMA, 309, 1268-1277. doi:10.1001/jama.2013.2024.

70. Miller, V. M., Redfield, M. M., \& McConnell, J. P. (2007). Use of BNP and CRP as biomarkers in assessing cardiovascular disease: diagnosis versus risk. Current Vascular Pharmacology, 5, 15-25.

71. Borlaug, B. A., \& Paulus, W. J. (2011). Heart failure with preserved ejection fraction: pathophysiology, diagnosis, and treatment. European Heart Journal, 32, 670-679. doi:10.1093/eurheartj/ ehq426.

72. Takimoto, E., Belardi, D., Tocchetti, C. G., Vahebi, S., Cormaci, G., Ketner, E. A., et al. (2007). Compartmentalization of cardiac betaadrenergic inotropy modulation by phosphodiesterase type 5 . Circulation, 115, 2159-2167. doi:10.1161/CIRCULATIONAHA. 106.643536.

73. Mishra, R. K., Li, Y., Ricardo, A. C., Yang, W., Keane, M., Cuevas, M., et al. (2013). Association of N-terminal pro-B-type natriuretic peptide with left ventricular structure and function in chronic kidney disease (from the Chronic Renal Insufficiency Cohort [CRIC]). The American Journal of Cardiology, 111, 432-438. doi:10.1016/j. amjcard.2012.10.019.

74. Duckles, S. P., \& Miller, V. M. (2010). Hormonal modulation of endothelial NO production. Pflügers Archiv-European Journal of Physiology, 459, 841-851.

75. Hamilton, C. A., Groves, S., Carswell, H. V., Brosnan, M. J., Graham, D., \& Dominiczak, A. F. (2006). Estrogen treatment enhances nitric oxide bioavailability in normotensive but not hypertensive rats. American Journal of Hypertension, 19, 859866. doi:10.1016/j.amjhyper.2006.01.008.

76. Nematbakhsh, M., \& Khazaei, M. (2004). The effect of estrogen on serum nitric oxide concentrations in normotensive and DOCA Salt hypertensive ovariectomized rats. Clinica Chimica Acta, 344, 5357. doi:10.1016/j.ccen.2004.01.019.

77. Brosnihan, K. B., Li, P., Figueroa, J. P., Ganten, D., \& Ferrario, C. M. (2008). Estrogen, nitric oxide, and hypertension differentially modulate agonist-induced contractile responses in female transgenic (mRen2)27 hypertensive rats. American Journal of Physiology Heart and Circulatory Physiology, 294, H1995-H2001. doi:10. 1152/ajpheart.01193.2007.

78. Bell, J. R., Bernasochi, G. B., Varma, U., Raaijmakers, A. J., \& Delbridge, L. M. (2013). Sex and sex hormones in cardiac stressmechanistic insights. Journal of Steroid Biochemistry and Molecular Biology. doi:10.1016/j.jsbmb.2013.05.015.

79. Beitelshees, A. L., Johnson, J. A., Hames, M. L., Gong, Y., CooperDehoff, R. M., Wu, J., et al. (2010). Aromatase gene polymorphisms are associated with survival among patients with cardiovascular disease in a sex-specific manner. PloS one, 5, e15180. doi:10.1371/journal.pone.0015180.

80. Jankowska, E. A., Biel, B., Majda, J., Szklarska, A., Lopuszanska, M., Medras, M., et al. (2006). Anabolic deficiency in men with chronic heart failure: prevalence and detrimental impact on survival. Circulation, 114, 1829-1837. doi:10.1161/CIRCULATIONAHA. 106.649426.

81. Reaves PY, Kirksey O, Britt EB, Holder MS (2009) Left ventricular hypertrophy,cardiac myocyte adaptation, and collagen/parenchymal distribution in response to subpressor and pressor doses of angiotensin II in Sprague-Dawley rats. The Internet Journal of Laboratory Medicine 3. doi:10.5580/10d9

82. Berk, B. C., Fujiwara, K., \& Lehoux, S. (2007). ECM remodeling in hypertensive heart disease. Journal of Clinical Investigation, 117, 568-575. doi:10.1172/JCI31044.

83. Sandberg K, Ji H (2012) Sex differences in primary hypertension. Biology of Sex Differences 3(1):7. doi:10.1186/2042-6410-3-7

84. Fischer, M., Baessler, A., \& Schunkert, H. (2002). Renin angiotensin system and gender differences in the cardiovascular system. Cardiovascular Research, 53, 672-677.

85. Stachenfeld, N. S., \& Keefe, D. L. (2002). Estrogen effects on osmotic regulation of AVP and fluid balance. American Journal of Physiology-Endocrinology and Metabolism, 283, E711-E721. doi:10.1152/ajpendo.00192.2002.

86. Hollenberg, N. K., Williams, G. H., Burger, B., Chenitz, W., Hoosmand, I., \& Adams, D. F. (1976). Renal blood flow and its response to angiotensin II. An interaction between oral contraceptive agents, sodium intake, and the renin-angiotensin system in healthy young women. Circulation Research, 38, 35-40.

87. Karjalainen, A. H., Ruskoaho, H., Vuolteenaho, O., Heikkinen, J. E., Backstrom, A. C., Savolainen, M. J., et al. (2004). Effects of estrogen replacement therapy on natriuretic peptides and blood pressure. Maturitas, 47, 201-208. doi:10.1016/S0378-5122(03)00279-2.

88. Kuroski de Bold, M. L. (1999). Estrogen, natriuretic peptides and the renin-angiotensin system. Cardiovascular Research, 41, 524-531.

89. Pendergrass, K. D., Pirro, N. T., Westwood, B. M., Ferrario, C. M., Brosnihan, K. B., \& Chappell, M. C. (2008). Sex differences in circulating and renal angiotensins of hypertensive $\mathrm{mRen}(2)$. Lewis 
but not normotensive Lewis rats. American Journal of Physiology Heart and Circulatory Physiology, 295, H10-H20. doi:10.1152/ ajpheart.01277.2007.

90. Dalpiaz, P. L., Lamas, A. Z., Caliman, I. F., Medeiros, A. R., Abreu, G. R., Moyses, M. R., et al. (2013). The chronic blockade of angiotensin I-converting enzyme eliminates the sex differences of serum cytokine levels of spontaneously hypertensive rats. Brazilian Journal of Medical and Biological Research, 46, 171-177.

91. Danser, A. H., Derkx, F. H., Schalekamp, M. A., Hense, H. W., Riegger, G. A., \& Schunkert, H. (1998). Determinants of interindividual variation of renin and prorenin concentrations: evidence for a sexual dimorphism of (pro)renin levels in humans. Journal of Hypertension, 16, 853-862.

92. Yusuf, S., Pfeffer, M. A., Swedberg, K., Granger, C. B., Held, P., McMurray, J. J., et al. (2003). Effects of candesartan in patients with chronic heart failure and preserved left-ventricular ejection fraction: the CHARM-Preserved Trial. Lancet, 362, 777-781. doi:10.1016/ S0140-6736(03)14285-7.

93. Massie, B. M., Carson, P. E., McMurray, J. J., Komajda, M., McKelvie, R., Zile, M. R., et al. (2008). Irbesartan in patients with heart failure and preserved ejection fraction. New England Journal of Medicine, 359, 2456-2467. doi:10.1056/NEJM oa0805450.

94. Gallagher, P. E., Li, P., Lenhart, J. R., Chappell, M. C., \& Brosnihan, K. B. (1999). Estrogen regulation of angiotensin-converting enzyme mRNA. Hypertension, 33, 323-328.

95. Kaplan, N. M., Kem, D. C., Holland, O. B., Kramer, N. J., Higgins, J., \& Gomez-Sanchez, C. (1976). The intravenous furosemide test: a simple way to evaluate renin responsiveness. Annals of Internal Medicine, 84, 639-645.

96. Schunkert, H., Danser, A. H., Hense, H. W., Derkx, F. H., Kurzinger, S., \& Riegger, G. A. (1997). Effects of estrogen replacement therapy on the renin-angiotensin system in postmenopausal women. Circulation, 95, 39-45.

97. Chen, Y. F., Naftilan, A. J., \& Oparil, S. (1992). Androgendependent angiotensinogen and renin messenger RNA expression in hypertensive rats. Hypertension, 19, 456-463.

98. Ellison, K. E., Ingelfinger, J. R., Pivor, M., \& Dzau, V. J. (1989). Androgen regulation of rat renal angiotensinogen messenger RNA expression. Journal of Clinical Investigation, 83, 1941-1945. doi: 10.1172/JCI114102.

99. Reckelhoff, J. F., Zhang, H., \& Srivastava, K. (2000). Gender differences in development of hypertension in spontaneously hypertensive rats: role of the renin-angiotensin system. Hypertension, 35, 480-483.

100. Leopold, J. A. (2011). Aldosterone, mineralocorticoid receptor activation, and cardiovascular remodeling. Circulation, 124, e466-e468. doi:10.1161/CIRCULATIONAHA.111.067918.

101. Liu, Y., Haddad, T., \& Dwivedi, G. (2013). Heart failure with preserved ejection fraction: current understanding and emerging concepts. Current Opinion in Cardiology, 28, 187-196. doi:10. 1097/HCO.0b013e32835c5492.

102. Krenning, G., Zeisberg, E. M., \& Kalluri, R. (2010). The origin of fibroblasts and mechanism of cardiac fibrosis. Journal of Cellular Physiology, 225, 631-637. doi:10.1002/jcp.22322.

103. Camelliti, P., Green, C. R., \& Kohl, P. (2006). Structural and functional coupling of cardiac myocytes and fibroblasts. Advances in Cardiology, 42, 132-149. doi:10.1159/000092566.

104. Weber, K. T. (2000). Fibrosis and hypertensive heart disease. Current Opinion in Cardiology, 15, 264-272.

105. Pellman, J., Lyon, R. C., \& Sheikh, F. (2010). Extracellular matrix remodeling in atrial fibrosis: mechanisms and implications in atrial fibrillation. Journal of Molecular and Cellular Cardiology, 48, 461-467. doi:10.1016/j.yjmcc.2009. 09.001 .
106. Zeisberg, E. M., Tarnavski, O., Zeisberg, M., Dorfman, A. L., McMullen, J. R., Gustafsson, E., et al. (2007). Endothelial-tomesenchymal transition contributes to cardiac fibrosis. Nature Medicine, 13, 952-961. doi:10.1038/nm1613.

107. Yoshimatsu, Y., \& Watabe, T. (2011). Roles of TGF-beta signals in endothelial-mesenchymal transition during cardiac fibrosis. Int $J$ Inflam, 2011, 724080. doi:10.4061/2011/724080.

108. Kang, N. N., Fu, L., Xu, J., Han, Y., Cao, J. X., Sun, J. F., et al. (2012). Testosterone improves cardiac function and alters angiotensin II receptors in isoproterenol-induced heart failure. Archives of Cardiovascular Diseases, 105, 68-76. doi:10.1016/j. acvd.2011.12.002

109. Hewitson, T. D., Zhao, C., Wigg, B., Lee, S. W., Simpson, E. R., Boon, W. C., et al. (2012). Relaxin and castration in male mice protect from, but testosterone exacerbates, age-related cardiac and renal fibrosis, whereas estrogens are an independent determinant of organ size. Endocrinology, 153, 188-199. doi:10.1210/en.2011-1311.

110. Altamirano, F., Oyarce, C., Silva, P., Toyos, M., Wilson, C., Lavandero, S., et al. (2009). Testosterone induces cardiomyocyte hypertrophy through mammalian target of rapamycin complex 1 pathway. Journal of Endocrinology, 202, 299-307. doi:10.1677/ JOE-09-0044.

111. Piera-Velazquez, S., \& Jimenez, S. A. (2012). Molecular mechanisms of endothelial to mesenchymal cell transition (EndoMT) in experimentally induced fibrotic diseases. Fibrogenesis \& Tissue Repair, 5(Suppl 1), S7. doi:10.1186/17551536-5-S1-S7.

112. Pedram, A., Razandi, M., O'Mahony, F., Lubahn, D., \& Levin, E. R. (2010). Estrogen receptor-beta prevents cardiac fibrosis. Molecular Endocrinology, 24, 2152-2165. doi:10.1210/me.2010-0154.

113. Wu, M., Han, M., Li, J., Xu, X., Li, T., Que, L., et al. (2009). 17betaestradiol inhibits angiotensin II-induced cardiac myofibroblast differentiation. European Journal of Pharmacology, 616, 155159. doi:10.1016/j.ejphar.2009.05.016.

114. Collier, P., Watson, C. J., Voon, V., Phelan, D., Jan, A., Mak, G., et al. (2011). Can emerging biomarkers of myocardial remodelling identify asymptomatic hypertensive patients at risk for diastolic dysfunction and diastolic heart failure? European Journal of Heart Failure, 13, 1087-1095. doi:10.1093/eurjhf/hfr079.

115. Devereux, R. B., Roman, M. J., Liu, J. E., Lee, E. T., Wang, W., Fabsitz, R. R., et al. (2003). An appraisal of echocardiography as an epidemiological tool. The Strong Heart Study. Annals of Epidemiology, 13, 238-244.

116. Palmieri, V., Dahlof, B., DeQuattro, V., Sharpe, N., Bella, J. N., de Simone, G., et al. (1999). Reliability of echocardiographic assessment of left ventricular structure and function: the PRESERVE study. Prospective Randomized Study Evaluating Regression of Ventricular Enlargement. Journal of the American College of Cardiology, 34, 1625-1632.

117. Gardin, J. M., Wagenknecht, L. E., Anton-Culver, H., Flack, J., Gidding, S., Kurosaki, T., et al. (1995). Relationship of cardiovascular risk factors to echocardiographic left ventricular mass in healthy young black and white adult men and women. The CARDIA study. Coronary Artery Risk Development in Young Adults. Circulation, 92, 380-387.

118. de Simone, G., Wallerson, D. C., Volpe, M., \& Devereux, R. B. (1990). Echocardiographic measurement of left ventricular mass and volume in normotensive and hypertensive rats. Necropsy validation. American Journal of Hypertension, 3, 688-696.

119. Devereux, R. B., Lutas, E. M., Casale, P. N., Kligfield, P., Eisenberg, R. R., Hammond, I. W., et al. (1984). Standardization of M-mode echocardiographic left ventricular anatomic measurements. Journal of the American College of Cardiology, 4, 1222-1230.

120. Levy, D. (1991). Clinical significance of left ventricular hypertrophy: insights from the Framingham Study. Journal of Cardiovascular Pharmacology, 17(Suppl 2), S1-S6. 
121. Gerdts, E., Okin, P. M., de Simone, G., Cramariuc, D., Wachtell, K., Boman, K., et al. (2008). Gender differences in left ventricular structure and function during antihypertensive treatment: the Losartan Intervention for Endpoint Reduction in Hypertension Study. Hypertension, 51, 1109-1114. doi:10.1161/HYPERTENSIONAHA. 107.107474.

122. Kolo, P. M., Omotoso, A. B. O., Katibi, I. A., Sanya, E. O., Adamu, U. G., Fasae, A. J., et al. (2008). Gender differences in left ventricular size and geometric pattern of hypertension subjects. The Cardiology, 4, 11-15.

123. Krumholz, H. M., Larson, M., \& Levy, D. (1995). Prognosis of left ventricular geometric patterns in the Framingham Heart Study. Journal of the American College of Cardiology, 25, 879-884. doi: 10.1016/0735-1097(94)00473-4.

124. Celentano, A., Palmieri, V., Arezzi, E., Mureddu, G. F., Sabatella, M., Di Minno, G., et al. (2003). Gender differences in left ventricular chamber and midwall systolic function in normotensive and hypertensive adults. Journal of Hypertension, 21, 1415-1423. doi:10.1097/01.hjh.0000059088.43904.ba.

125. Lang, R. M., Bierig, M., Devereux, R. B., Flachskampf, F. A., Foster, E., Pellikka, P. A., et al. (2006). Recommendations for chamber quantification. European Journal of Echocardiography, 7, 79-108. doi:10.1016/j.euje.2005.12.014.

126. Foppa, M., Duncan, B. B., \& Rohde, L. E. (2005). Echocardiography-based left ventricular mass estimation. How should we define hypertrophy? Cardiovascular Ultrasound, 3, 17.

127. Afonso, L. C., Bernal, J., Bax, J. J., \& Abraham, T. P. (2008). Echocardiography in hypertrophic cardiomyopathy: the role of conventional and emerging technologies. JACC: Cardiovascular Imaging, 1, 787-800. doi:10.1016/j.jcmg.2008.09.002.

128. Nagueh, S. F., Appleton, C. P., Gillebert, T. C., Marino, P. N., Oh, J. K., Smiseth, O. A., et al. (2009). Recommendations for the evaluation of left ventricular diastolic function by echocardiography. European Journal of Echocardiography, 10, 165-193. doi:10.1093/ejechocard/jep007.

129. Palmeri, M. L., \& Nightingale, K. R. (2011). Acoustic radiation force-based elasticity imaging methods. Interface Focus, 1, 553564. doi:10.1098/rsfs.2011.0023.

130. Pernot, M., Couade, M., Mateo, P., Crozatier, B., Fischmeister, R., \& Tanter, M. (2011). Real-time assessment of myocardial contractility using shear wave imaging. Journal of the American College of Cardiology, 58, 65-72. doi:10.1016/j.jacc.2011.02.042.
131. Kolipaka, A., McGee, K. P., Araoz, P. A., Glaser, K. J., Manduca, A., Romano, A. J., et al. (2009). MR elastography as a method for the assessment of myocardial stiffness: comparison with an established pressure-volume model in a left ventricular model of the heart. Magnetic Resonance in Medicine, 62, 135-140. doi:10. $1002 / \mathrm{mrm} .21991$.

132. Wadman, M. (2013). NIH mulls rules for validating key results. Nature, 500, 14-16. doi:10.1038/500014a.

133. Beery, A. K., \& Zucker, I. (2011). Sex bias in neuroscience and biomedical research. Neuroscience and Biobehavioral Reviews, 35 , 565-572. doi:10.1016/j.neubiorev.2010.07.002.

134. Raz, L., \& Miller, V. M. (2012). Considerations of sex and gender differences in preclinical and clinical trials. Handb Exp Pharmacol, vol 214. Berlin: Springer-Verlag. doi:10.1007/9783-642-30726-3_7.

135. Yang, X., Schadt, E. E., Wang, S., Wang, H., Arnold, A. P., IngramDrake, L., et al. (2006). Tissue-specific expression and regulation of sexually dimorphic genes in mice. Genome Research, 16, 9951004.

136. Isensee, J., \& Ruiz Noppinger, P. (2007). Sexually dimorphic gene expression in mammalian somatic tissue. Gender Medicine, 4(Suppl B), S75-S95.

137. Isensee, J., Witt, H., Pregla, R., Hetzer, R., Regitz-Zagrosek, V., \& Noppinger, P. R. (2008). Sexually dimorphic gene expression in the heart of mice and men. Journal of Molecular Medicine, 86, 61-74.

138. Sandberg, K., \& Verbalis, J. G. (2013). Sex and the basic scientist: is it time to embrace Title IX? Biology of Sex Differences, 4, 13. doi: 10.1186/2042-6410-4-13.

139. Heinrich J (2001) General Accounting Office, GAO-01-286R Drugs Withdrawn From Market.

140. Goodarzi, M. O., Li, X., Krauss, R. M., Jrotter, J. I., \& Chien, Y. I. (2013). Relationship of sex to diabetes risk in statin trials. Diabetes Care, 36, e100-e101.

141. Shub, C., Klein, A. L., Zacharial, P. K., Bailey, K. R., \& Tajik, A. J. (1994). Determinations of left ventricular mass by echocardiography in a normal population: effect of age and sex in addition to body size. Mayo Clinic Proceedings, 69, 205-211.

142. Kolipaka, A., Aggarwal, S. R., McGee, K. P., Anavekar, N., Manduca, A., Ehman, R. L., et al. (2012). Magnetic resonance elastography as a method to estimate myocardial contractility. Journal of Magnetic Resonance Imaging, 36, 120-127. doi:10. 1002/jmri.23616. 